University of Windsor

Scholarship at UWindsor

$11-10-2015$

\title{
Role taking and knowledge building in a blended university course
}

D. Cesareni

S. Cacciamani

N. Fujita

University of Windsor, nfujita@uwindsor.ca

Follow this and additional works at: https://scholar.uwindsor.ca/open-learningpub

Part of the Curriculum and Instruction Commons, Higher Education Commons, and the Online and Distance Education Commons

\section{Recommended Citation}

Cesareni, D.; Cacciamani, S.; and Fujita, N.. (2015). Role taking and knowledge building in a blended university course. International Journal of Computer-Supported Collaborative Learning, 11 (1), 9-39. https://scholar.uwindsor.ca/open-learningpub/7

This Article is brought to you for free and open access by the Office of Open Learning at Scholarship at UWindsor. It has been accepted for inclusion in Office of Open Learning Publications by an authorized administrator of Scholarship at UWindsor. For more information, please contact scholarship@uwindsor.ca. 


\title{
Effects of role taking in online writing and reading activities for knowledge building in a blended university course
}

\author{
Donatella Cesareni1 $^{1}$, Stefano Cacciamani², Nobuko Fujita ${ }^{3}$
}

\begin{abstract}
Role taking is an established technique for promoting social cognition. Playing a specific role within a group could lead students to exercise collective cognitive responsibility for collaborative knowledge building. Two studies explored the effects of role taking on participation in a blended university course. Students participated in the same knowledge-building activity over three consecutive, five-week modules and enacted four roles. In Study 1, 59 students were distributed into groups with two conditions: students who took a role in Module 2 and students who did not take a role, using Module 1 and 3 as pre and post tests. Results show no differences in participation in Module 1, higher levels of writing and reading for students with a role in Module 2, and this pattern sustained in Module 3. Students with the Synthesizer role was the most active in terms of writing and the second most active for reading; students with the Social Tutor role were the most active for reading. In Study 2, 143 students were divided into groups with two conditions: students who had a role in Module 1 and students who did not have a role. Content analysis reveals that students with roles tended to vary their contributions more than students without roles by proposing more problems, synthesizing the discourse, reflecting on the process and organization of activity. They also assumed correct responsibilities for their role: the Skeptic prioritizes questioning of content, the Synthesizer emphasizes synthesizing of content, and the Social Tutor privileges maintaining of relationships.
\end{abstract}

\section{Keywords}

Computer-mediated communication * Cooperative/collaborative learning * Pedagogical issues Teaching/learning strategies * Post-secondary education * Knowledge building

\footnotetext{
${ }^{1}$ Donatella Cesareni

donatella.cesareni@uniroma1.it

Univesity of Rome "Sapienza,” Via Dei Marsi 78, 00185 Rome, Italy

${ }^{2}$ Stefano Cacciamani

s.cacciamani@univda.it

University of Valle d'Aosta, Italy

${ }^{3}$ Nobuko Fujita

nfujita@uwindsor.ca

University of Windsor, Windsor, ON, Canada
} 


\section{Introduction}

Over the past several years, a new generation of Internet technologies, called Web 2.0, has been developed, providing the opportunity to support new practices of teaching and learning in higher education. Web forums, wikis, chats, virtual worlds, and social networks represent a level of evolution of digital technology that is characterized by the expansion of opportunities for interaction among users (O'Reilly, 2005). To stress this idea, Selwyn (2012) defines these technologies as "social media" and identifies two main characteristics:

1. They are based on open and shared digital content that can be produced, criticized, and reconfigured by a wide audience of users. Previously drawn distinctions between providers and users become problematized as participants can be both users and content producers, in turn.

2. All practices linked to social media are described in terms of socialization and participation: they enable collective actions carried out by the network user groups online that are driven by the desire to build social relationships and oriented to participate in the activities that take place through these practices.

Some observers are beginning to recognize that the social nature of learning and knowledge using social media confounds education's traditional focus on helping individual students master welldefined bodies of stable knowledge (Hickey, McWilliams, \& Honeyford, 2011). Digital social networks are continually shaped by shared control (where content and expertise are continually cocreated by participants) and transformative interaction (where individual users and groups of users customize both the content and the format for their use) (Xenos \& Foot, 2008).

The use of Web 2.0 technologies in online courses in higher education has, then, been conceptualized with reference to the idea of "community." Black, Dawson, and Priem (2008) highlight that, in the last 10 to 15 years, online learning researchers and instructional professionals have promoted the significance of community in online learning environments. Wallace (2003) states that community in online environments arises at the intersection of three contemporary topics in educational research: social learning theories, affordances of computers as communication devices, and the increased utilization of learning theories in online course development.

Different models of communities inspired by a socio-constructivist perspective have recently been developed for online educational course contexts. For instance, the Community of Inquiry (COI; Garrison, Anderson, \& Archer, 2000) model assumes that to promote deep and meaningful learning it is necessary to involve online course participants in a collaborative inquiry activity through the development of three interdependent elements: "cognitive presence," "social presence," and "teaching presence." The Knowledge Building Community (KBC) model (Scardamalia \& Bereiter, 1999; 2006; 2010) suggests that we can re-conceptualize the classroom as a collaborative community involved in an inquiry activity, in which each member assumes "collective cognitive responsibility" for the group's knowledge building process and makes a commitment to investigate and discuss real ideas and authentic problems. The goals for this community thus become the progressive refinement of ideas and the building of increasingly coherent theories explaining the phenomena under investigation.

Both COI and KBC models stress the idea that the main goal of online courses in higher education is to build new knowledge in and for the community through a deep collaboration between students and teachers. Therefore, online courses supported by Web 2.0 technologies require, more strongly than in the past or compared to face-to-face instructional practices, the active participation of their students. 
DOI 10.1007/s11412-015-9224-0

Student participation in online courses

Research in online learning defines "participation" as involving different forms of communication (e.g. content related, planning of task, and social support) and demanding different units of analysis (Hrastinski, 2008). Participation may be detected by a quantitative approach, using numerical indicators such as the number of visits to the platform, the number of written messages or read messages, and the relationship between the reading and writing. Participation can also be analyzed through a qualitative content analysis of the messages to identify their discursive functions (Cacciamani et al., 2012). The main risk for student participation in an online course is represented by the phenomenon of "lurking": this practice refers to students who limit their action in an online environment to reading messages without posting any messages (Morris \& Ogan, 1996). Lurkers in the online course discussion context are students who remain very passive during most of or throughout the entire collaborative process; their contributions often contain false promises or reflect some problems that they had in the past, aimed at apologizing for a lack of commitment to the group. Moreover, in most cases, lurkers have a vested interest in staying onboard with the group task - mostly for personal learning gain - but their participation is very minimal and consists more frequently of reflective comments than contributions of new knowledge (Strijbos \& De Laat, 2010).

Nonneke and Preece (2001) suggest that there are many reasons why people lurk. Some are unsociable or even selfish, but many are not: lurking also enables new members to learn community norms, see if their concerns are relevant, and obtain vicarious support without disclosing themselves. Depending on the perspective from which it is judged, lurking may or may not be a problematic behavior (Preece, Nonnecke, \& Andrews, 2004). Lurking might be considered a form of participation from a social constructivist approach, insofar as lurkers are often involved in the search for connections within the forum messages and the practice can be used to identify points of entry into the discussion (Nonnecke \& Preece, 2001; Hickey, McWilliams, \& Honeyford, 2011). If there are few or no messages being posted in an online community, however, the community cannot survive. Therefore, designers of online courses seek strategies to encourage all students to participate in posting messages and to sustain the online community, such as introducing roles.

\section{Roles in online courses}

A "role" can be defined in terms of a system of functions that people can assume in a group to guide individual behaviors and regulate group interactions among the group members. Taking a role means being "associated with a position in a group with rights and duties toward one or more other group members" (Hare, 1994, p. 434). In an educational context, role taking can promote individual responsibility and group cohesion, as well as positive interdependence (Strijbos \& Weinberger, 2010). Furthermore, taking a role can also facilitate a group member's awareness of peer contributions and the group's overall performance (Strijbos, Martens, Jochem, \& Broers, 2004). For collaborative knowledge building, the roles that individuals take in a group can be viewed as "multiple interpretive perspectives that conflict, stimulate, intertwine and be negotiated" in a community (Stahl, 2006, p. 4).

In recent years, the concept of a "role" has been studied in the field of Computer-Supported Collaborative Learning (CSCL) as a factor supporting students' collaborative learning activity. Two main perspectives characterize this field of study: the emerging roles perspective, which focuses on the roles that participants develop spontaneously during their collaborative learning activity; and the scripted roles perspective, which focuses on how the collaborative learning process can be facilitated by structuring and prescribing roles and activities to learners (Strijbos \& Weinberger, 2010). The first perspective emphasizes that learners structure and self regulate their online learning activity, thereby each developing a personal learning style; this development then leads to a number of "emerging roles" that the students assume to facilitate structuring and regulating group work. The second perspective highlights the relevance of designed roles as instructional supports to improve both the processes and the outcomes of online collaborative learning. These "scripts" are 
DOI 10.1007/s11412-015-9224-0

defined as instruction-providing information about the actions appropriated to specify and externalize the roles that are expected to be assumed by students during a collaboration activity (Weinberger, Stegman, \& Fisher, 2010). Since these scripts function to scaffold a collaborative learning activity, some authors prefer to use the expression "collaboration scripts" (Kollar, Fischer, $\&$ Hesse, 2006).

From the collaborative knowledge building perspective, "scripted roles" can be defined in terms of "conversational functions" or specific kind of activities performed in a discussion that is expected to support productive interaction (Wise et al. 2012). The conversational functions frequently included in the roles assigned to the students in on line discussion are to: motivate others to contribute; give direction to the conversation; provide new ideas; use theory to ground the discussion; bring in (relevant external) sources; respond to previous comments; and summarize existing contributions (Wise et al, 2012). Defining roles as conversational functions that create positive interdependence among participants aligned with the common goal to advance the community knowledge avoids the risk of focusing on tasks and activities as roles, from this perspective, become supports enacted by the students to sustain collaborative interactions oriented toward knowledge building.

Many researchers have emphasized the usefulness of such scripted roles in educational contexts. For example, Wilensky and Stroup (1999) integrated role-playing activities via participatory simulations into science classes. In their work, students could simulate the role of a predator or prey in an ecosystem and engage in a class-wide discussion of the resultant global population dynamics. Wilensky and Stroup argued that role taking can increase students' motivation and understanding of complex systems.

Despite this large interest in roles, only a few empirical studies analyze the effect of role taking on students' participation in blended online courses in an academic context. For instance, Brewer and Klein (2006) investigated the effects of roles based on different types of interdependence for collaborative learning: roles, rewards, roles-plus-rewards, or no structure in an online asynchronous collaborative learning environment. College students worked together in small discussion groups for seven days. The results showed that participants in the groups with roles-plus-rewards interacted with their peers significantly more than those who were given only the reward or those without the condition of interdependence. A significant correlation showed that participants with a high number of interactions also obtained higher scores in the post-test of the learning content. Similarly, Spadaro, Sansone, and Ligorio (2009) found that in-service teachers enrolled in a Master's-level blended course reach the highest level of participation, in terms of writing and reading, when they can play two roles in the course: Tutor, acting to promote forum discussion, and Editor, supervising collaborative writing tasks. Wise and Chiu (2011) introduced an approach to analyzing temporal pattern of knowledge construction (KC) in online discussion, including consequences of roles assignment in a blended university course. Their results show that assigning a summarizing role mid-discussion can aid group progress to more advanced phases in $\mathrm{KC}$. In a study investigating online collaborative modules in a teacher preparation course based on a blended approach, Pozzi (2011) introduced a role playing activity. The scripted, not assigned, roles were: Coach, Bureaucrat, Defeatist, Wise, Techno-skeptical, Techno-loving, Efficiency-minded, School Principal and Rapporteur. Results show that roles that students chose helped them to develop a certain awareness of the collaborative learning process.

The few studies that analyzed role taking in blended courses highlight that the assumption of a role guides the activity of individual students, provides them with a script with which to act, and regulates their interactions within the group. Additionally, the possibility of playing a specific role within the group leads students to exercise greater responsibility for the community's own knowledge building activity. To investigate in depth the effects of role taking on reading and writing activity or participation in a knowledge building in an online higher education course, we conducted two studies. 
DOI 10.1007/s11412-015-9224-0

\section{Research questions}

The current research focused on four main research questions:

1. Does taking on a role in a group in an online course lead to a higher level of participation in knowledge building in terms of writing and reading activity?

2. Which specific types of roles foster a higher level of participation?

3. Does taking on a role influence the conversational functions of the messages students post compared with those posted by students who do not take a role?

4. Are there also differences between roles in the conversational functions of the messages posted?

We conducted two separate studies to answer these questions. The first study examined research questions 1 and 2, and the second study examined research questions 3 and 4 . In the following sections, we first describe the setting and the online environment, which was the same for both two studies. Second, we present the different methods and results for Study 1 and Study 2 in separate sections. Finally, we discuss the overall findings in the general discussion section.

\section{Setting and online environment}

Throughout the second semester of the first year in a Pedagogy course at the Sapienza University of Rome, students were asked to participate in a blended knowledge-building activity during the course in addition to attending lectures. Students voluntarily chose to take part in the blended activity, and their participation was assessed as part of the course. Participants were distributed into discussion groups of 10-12 students. In these groups they interacted both face-to-face in class and online, sharing their ideas and collaboratively building artifacts, for example a concept map of the group's shared understanding, to present during the larger lecture hall sessions. Online activities took place during the same period of time as the lectures and were divided into three consecutive, five-week modules. In each module, students were asked to analyze, discuss, and reflect on different themes connected to the course curriculum, and to build a concept map or a short power point presentation at the end of the activity. The group composition remained the same during the three modules. Students that agreed to participate in the blended activity received a score from 6 to 12 points according to their involvement in group activity, assessed not in relation with the amount of written notes but with the quality of their contribution to collective knowledge building. At the end of the course their knowledge was assessed with a final test, with a maximum score of 20 points, added to participation score in order to determinate the final grade that in Italy is computed on 30 .

143 students (22 males, 121 females), aged 18-30 years, participated in the activity, distributed in 14 discussion groups. In such large classes of university students, used to traditional pedagogy, it is very difficult to introduce knowledge-building habits. In large university student groups, in order to create conditions for knowledge building, is crucial to organize and model student participation (Hmelo-Silver and Barrows, 2008). Not having enough facilitators to moderate group discussion for all 14 groups, we choose to assign to students specific roles in turns that could suggest and model principal discourse moves related to "conversational functions" that are particularly important for knowledge building. These particular roles were designed in order to support group discussion and to create, through a positive interdependence, collective cognitive responsibility (Scardamalia, 2002) toward advancement of the community knowledge. At the beginning of each module, the instructor randomly asked four students in each group to take on a role, giving students some 
DOI 10.1007/s11412-015-9224-0

instructions but leaving them freedom on how to enact the role ${ }^{4}$. They could accept or decline the role, without being penalized for refusing the role. At the end of the module they stopped to act the role and other students were asked to. Some students did not take on any role in the activity.

Four roles were specially designed to help students put into practice the main knowledgebuilding know-how: 1) "Social Tutor"; 2) "Synthesizer"; 3) "Map-Responsible" (responsible for the concept map); and 4) "Skeptic." The Social Tutor had the task of promoting participation of all the members of the group, aligned with the principle of collective cognitive responsibility. The Synthesizer was to produce a synthesis of group discussions every week, bringing out the main questions and presenting them again to the group, fostering in this way the importance of rise-above notes. In knowledge building, rise-above notes are used to subsume selected previous notes, synthesize ideas, create historical accounts and archives, reduce redundancy, and impose a higherlevel organization on ideas (Scardmalia \& Bereiter, 2006). The Map-Responsible was the "technology mediator" of the group, responsible for installing on his/her laptop the software needed for creating a concept map during the face to face group discussion and for presenting the map to other groups in the hall session. Consistent with the knowledge building principle of "improvable ideas" (Scardamalia, 2002), the Skeptic was asked to bring statement up for discussion again, avoiding commonplace ideas in the group, in order to generate "prolific doubts". This last role has to remain unknown to other students, while the other roles were known to all the participant in the group.

Students interacted online in a Moodle (Modular Object Oriented Dynamic Learning Environment) e-learning environment (http://elearning.uniroma1.it) that is used to deliver more than 1,000 courses to about 70,000 users. Moodle is a flexible learning environment that provides traditional educational tools (course management, assessment tests, exercises, etc.), but also offers interactive tools like chat, forum, and wiki that are particularly interesting for promoting a constructivist educational approach. In addition, we chose Moodle both for its accessibility as free and open source software and for its usability in enabling students to access it from any browser.

In Moodle there are three different categories of users: administrator, teacher, and student. Teachers can use the educational tools provided by the system to manage courses, prepare the learning environment, and facilitate and monitor the learning activities. Students can use learning objects or any digital resources available in the Moodle environment and participate in interactive activities.

In the Moodle activity on pedagogy, the lecturer organized 14 different online course databases, one for each group, using interactive tools like a forum, the collaborative building of a glossary, and the sharing of documents and artifacts collaboratively produced by students. An important pedagogical method to avoid user disorientation in an online learning environment is to let the environment "grow" in an emergent way with the group's activities. At the beginning, the online learning environments presented to different groups offered few elements visible by students (Figure 1). Modules and tools were gradually introduced to enrich the environment as new activities started.

\footnotetext{
${ }^{4}$ For example students could receive an e-mail like this: "Dear... I propose you to take on the role of social tutor in your discussion group. Your task is to foster group participation, make sure that there are no debates between only two or three people and / or someone is excluded from the activity. Let me know if you accept to take on this role"
} 
DOI 10.1007/s11412-015-9224-0

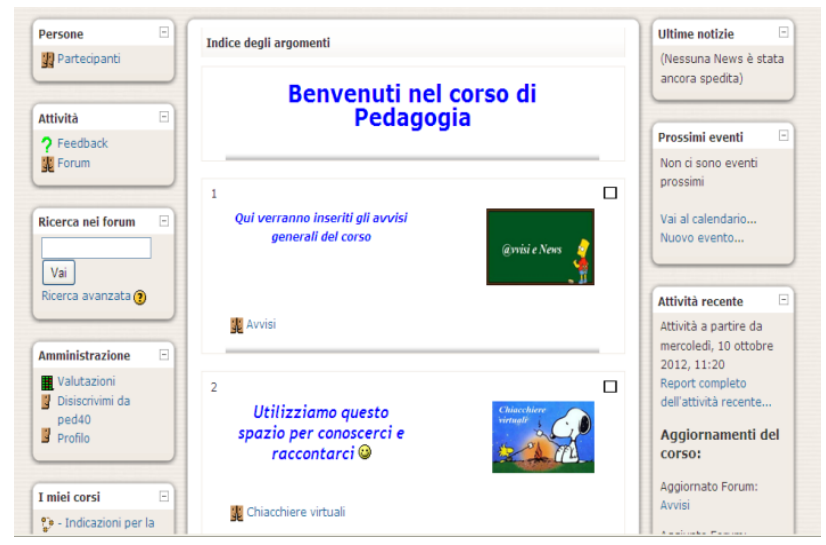

Figure 1. The online environment at the beginning of the activity

\section{Study 1: Role taking and levels of participation}

\section{Study 1 Method}

\section{Study 1 Participants}

From the 143 participants in the blended activity, we selected for this first study two particular groups of students (59 students, 7 males and 52 females):

a) participants who acted a role only in Module 2 (31 students)

b) participants without a role over three different modules of the Moodle activity (28 students)

\section{Study 1 Procedure}

The first study investigated whether taking a role leads students to a higher level of participation and which specific role fosters a higher level of participation $\left(1^{\text {st }}\right.$ and $2^{\text {nd }}$ research questions $)$. To answer the first research question, we compared the participation (in terms of both the number of messages posted and read in the knowledge-building forums) in the three different modules of the Moodle activity (Module 1, Module 2, and Module 3) among two groups of students: 1) Students who only took a role in Module 2 (With role in Module 2); and 2) students who did not take on a role at all (Without role). In Module 1, none of the students in the two conditions took a role in the group. In Module 2, students in the group "With role in Module 2" assumed the roles mentioned above in their group. In Module 3, again none of the students of these two groups held particular roles (see Table 1). So we can consider Module 1 as a pre-test, we introduce a design variable in Module 2 and measure its effects in Module 3. Students "with role" and "without role" were extracted from the same 14 discussion groups.

Table 1 Research Design for the First Study

\begin{tabular}{llll}
\hline & Module 1 & Module 2 & Module 3 \\
\hline With role in Module 2 $(n=31)$ & No role & With role & No role \\
\hline Without role $(n=28)$ & No role & No role & No role \\
\hline
\end{tabular}

For the second research question we compared the writing and reading activity of the 31 students of the group "with role". 
DOI 10.1007/s11412-015-9224-0

As mentioned before the roles were "Social Tutor," "Synthesizer," "Map-Responsible," and "Skeptic." Students who were asked to take a role received an e-mail from the lecturer with instructions explaining what they were supposed to do for their roles.

Study 1 Measures and data analyses

The data corpus consists of the knowledge-building activity carried out by students in three different modules. This activity was analyzed using a quantitative approach to evaluate students' participation both in terms of the number of messages written and messages read in all discussions in the three modules that occurred consecutively.

For the first research question, as stated before, we compared the participation between students "With role in Module 2" and students "Without role" across two different modules, using Module 1 as a pre-test and Module 3 as post-test. We analyzed differences using the Student t-test because it was not possible to apply the ANOVA due to insufficient statistical conditions.

In order to answer to the second research question, which explores roles that foster a higher level of participation, we compared in a descriptive way the quantitative indicators of writing and reading activity among students with the different roles.

\section{Study 1 Results.}

Research Question 1: Does taking on a role in a group in an online course lead to a higher level of participation in knowledge building, in terms of writing and reading activity?

Table 2 Writing Messages

\begin{tabular}{lllll}
\hline Module & Group & $N$ & Mean & $\begin{array}{c}\text { Standard } \\
\text { Deviation }\end{array}$ \\
\hline Module 1 & Without role & 28 & 4.92 & 7.16 \\
\cline { 2 - 5 } & With role in M2 & 31 & 4.16 & 3.56 \\
\hline Module 3 & Without role & 28 & 3.75 & 6.63 \\
\cline { 2 - 5 } & With role in M2 & 31 & 8.48 & 6.87 \\
\hline
\end{tabular}

Comparing students "Without role" to students "With role in Module 2 (M2)," we can see that taking a role has a positive effect on writing activity (Table 2 and Figure 2). The two groups did not differ on writing activity in the pre-test or Module $1(t(59)=-0.53, \mathrm{p}>.05)$, before the introduction of the roles. Significant differences emerged in the post-test or Module $3(t(59)=-2,68, \mathrm{p}=.01)$. The students "With role in Module 2" wrote a higher number of messages in the web-forum.

Table 3 Reading Messages

\begin{tabular}{llllc}
\hline Module & Group & $N$ & Mean & $\begin{array}{c}\text { Standard } \\
\text { Deviation }\end{array}$ \\
\hline Module 1 & Without role & 28 & 27.14 & 41.07 \\
\cline { 2 - 5 } & With role in M2 & 31 & 34.90 & 36.14 \\
\hline Module 3 & Without role & 28 & 24.50 & 41.61 \\
\cline { 2 - 5 } & With role in M2 & 31 & 60.03 & 66.37 \\
\hline
\end{tabular}


DOI 10.1007/s11412-015-9224-0

A similar pattern is found in the reading activity (Table 3 and Figure 3). Again, no differences are found between the two groups in the pre-test or Module $1(t(59)=-0,77, \mathrm{p}>.05)$. In the post-test or Module 3, the students "With role in Module 2" read a higher number of messages compared to their counterparts $(t(59)=-2,43, \mathrm{p}=.018)$. Figure 2 and 3 show evidence for increased participation starting in Module 2 (both in writing and reading messages) among students who took a role in that period.

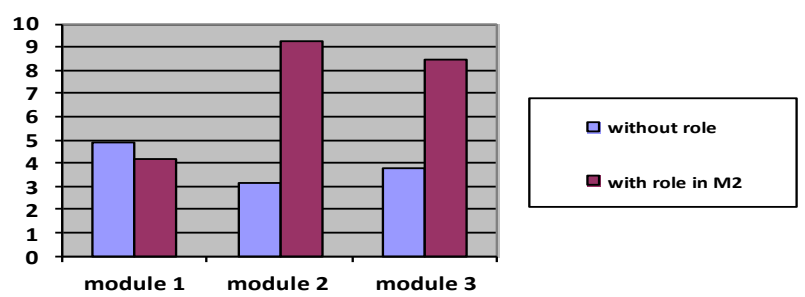

Figure 2 Writing activities in the three modules

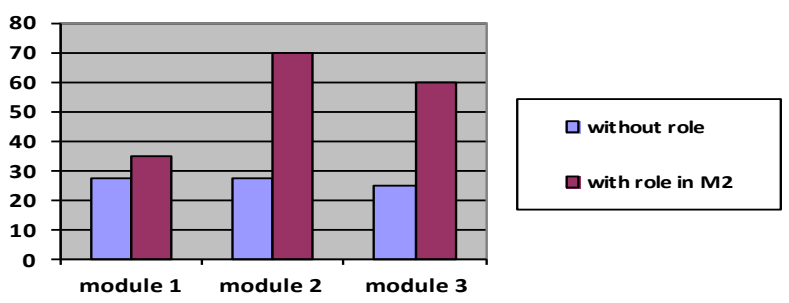

Figure 3 Reading activities in the three modules

Research Question 2: Which type of role fosters a higher level of participation?

To answer research question 2, we analyzed the participation of students in light of the particular kinds of roles they assumed (Table 4 and 5).

Table 4 Messages Written by Students with Different Roles ${ }^{5}$

\begin{tabular}{ll}
\hline Role & Module 2 \\
\hline
\end{tabular}

\footnotetext{
${ }^{5}$ Differences in numbers among the four types of roles are due to the fact that we consider only students that acted a role only in module 2 . We had 14 groups, so 14 Synthesizer for each module, but we consider here only nine students who took the role of Synthesizers because the other five students (14groups, 14 synthesizers) also had a role in module 1 or 3 , and are not taken in consideration for this first study. The same applies for the other roles.
} 


\begin{tabular}{lc}
\multicolumn{2}{l}{ DOI 10.1007/s1 1412-015-9224-0 } \\
\hline Synthesizer (9) & $10.24(5.09)$ \\
\hline Social Tutor (7) & $9.50(2.71)$ \\
\hline Skeptic (6) & $8.70(4.85)$ \\
\hline Map-Responsible (9) & $7.00(4.71)$ \\
\hline
\end{tabular}

As shown in Table 4, the students who held the role of Synthesizer (of the group discussion) were most active in writing, followed by the students in the Social Tutor role. Students in the MapResponsible role were the less involved in the discussion.

Table 5 Messages Read by Students with Different Roles

\begin{tabular}{lc}
\hline Role & $\begin{array}{c}\text { Module 2 } \\
M(S D)\end{array}$ \\
\hline Synthesizer (9) & $73.94(63.17)$ \\
\hline Social Tutor (7) & $77.30(42.68)$ \\
\hline Skeptic (6) & $69.10(44.58)$ \\
\hline Map-Responsible (9) & $51.46(34.97)$ \\
\hline
\end{tabular}

As seen in Table 5, the students who held the role of Social Tutor were the most active in the reading activities, followed by the Synthesizers). Similar to the findings for writing, the students in the Map-Responsible role were the less involved in reading the messages.

\section{Study 2: Role taking and the content of online contributions}

\section{Study 2 Method}

\section{Study 2 Participants}

The second study involved all the143 students (12 males, 121 females) divided in two conditions:

Condition 1: 53 students who had a role in Module 1

Condition 2: 90 students who did not have a role in Module 1

\section{Study 2 Procedure}

In the second study we investigated if taking on a role results in differences in the content of messages students posted compared with students who do not take on a role, and if are also differences between the roles in the content of message posted in terms of their "conversational functions" (Research Questions 3 and 4). In order to answer the two research questions, we qualitatively analyzed the content of the messages written by the students in the discussions of Module 1 comparing Condition 1 (with role) and 2 (without role). We chose to analyze discussions in Module 1 because students in all the groups discussed the same topic: how can we depict a "good teacher." In Condition 1, the same roles as presented in the first study were implemented. 
DOI 10.1007/s11412-015-9224-0

\section{Study 2 Measures and data analysis}

We used a content analysis coding scheme that was designed by the authors in previous research in order to analyze students' contribution to the online discussion. The categorization is based on a synthesis of theoretical approaches that considers students as contributors to knowledge building: Pontecorvo's (1987) “discussing for reasoning” approach, Muukkonen, Hakkarainen, \& Lakkala's (2004) Progressive Inquiry Model, Wise et al.'s (2012) “conversational functions” approach to scripted roles, and Scardamalia and Bereiter's (2006)'s Knowledge Building. Hmelo-Silver and Barrows (2008) consider three kind of discourse moves that are especially important in knowledge building: questioning; making statements, that can be simple assertion or reformulation or elaboration of an idea; making regulatory statements directed at collaboration and learning processes. They also underline the importance of metacognitive statements that can support group work.

Starting from these discourse moves and aligned with Scardamalia and Bereiter's (2006) Knowledge Building pedagogy, we considered four types of global conversational functions that can contribute to collaborative knowledge building.

The first step in contributing to collaborative knowledge building is to introduce new ideas into group discourse, in form of problem or statements that introduce new contents. Next, in order to increase collective knowledge and enhance interdependence, students build on each other ideas, synthesizing what has already been said (by themselves or others) reinforcing, clarifying, and improving existing knowledge; an important contribute to the group discourse is given by metacognitive reflections and evaluations of ideas and/or process (transformative distributed evaluation); in order to create collaboration and enhance collective responsibility for knowledge building, it is also important to foster social relationships within the group.

Therefore, the coding scheme we designed consists of four categories that we defined "global conversational functions" and further subcategories that we defined "specific conversational functions that characterizes all of the students' contributions to the forum, as shown in the Table 6 below.

Table 6 Coding Scheme for Content Analysis

\begin{tabular}{|c|c|}
\hline Categories & Subcategories and examples \\
\hline \multirow{5}{*}{$\begin{array}{l}\text { To introduce new } \\
\text { problems or contents }\end{array}$} & $\begin{array}{l}\text { A1. Introducing a personal idea or theory: "The ideal teacher should be empathic, attentive to } \\
\text { students' requirements, flexible ..." }\end{array}$ \\
\hline & $\begin{array}{l}\text { A2. Introducing information obtained from reliable sources: "I read in the textbook that ..."; } \\
\text { "Studies on expert teachers say ..." }\end{array}$ \\
\hline & $\begin{array}{l}\text { A3. Introducing examples drawn from student experience: "This ability was totally absent in the } \\
\text { teachers of the school I attended"; "Today I listened to a really shameful discussion..." }\end{array}$ \\
\hline & $\begin{array}{l}\text { A4. Introducing information obtained during lectures: "As professor said yesterday during the } \\
\text { lecture ..." }\end{array}$ \\
\hline & $\begin{array}{l}\text { A5. Posing research questions or problems: "How much, in school achievement, depends on us, } \\
\text { and how much do we rely on the teacher?" }\end{array}$ \\
\hline \multirow{5}{*}{$\begin{array}{l}\text { B. To take up or revise } \\
\text { previous information } \\
\text { or theories }\end{array}$} & $\begin{array}{l}\text { B1. Elaborating their own ideas (i.e. to clarify or widen ideas or theories): "To clarify, I wanted to } \\
\text { say that the teacher has to ..." }\end{array}$ \\
\hline & $\begin{array}{l}\text { B2. Elaborating others' idea (To explicitly refer to another's opinion in order to amplify contents): } \\
\text { "I agree with Laura about the qualities of a good teacher, and in particular, I want to specify that this } \\
\text { flexibility..." }\end{array}$ \\
\hline & $\begin{array}{l}\text { B3. Synthesizing: "I'm trying to make a list and add my contribution starting from qualities } \\
\text { mentioned by the group: competent, fond of his work, good observer ..." }\end{array}$ \\
\hline & $\begin{array}{l}\text { B4. Repeating content proposed by others (without elaborating): "For example, Elisabeth says } \\
\text { that a good teacher ..." }\end{array}$ \\
\hline & 5. Repeating their own contribution: "I reaffirm that if a student, despite his teacher's attempt to \\
\hline
\end{tabular}


C. To evaluate or reflect

D. To foster and/or maintain relations
C1. Expressing metacognitive reflection (on a process carried out or organization of cognitive activity): "We are here to confront our point of view ..."; "If you agree, I propose to use this list for going on ...."

C2. Expressing metacognitive reflection on content: "Some points of this statement let me reflect on ..."

C3. Commenting, evaluating: "Perhaps it's for this reason that it's difficult to be a good teacher..."

D1.Expressing agreement (plain expressions of agreement, without any comment or new contents): "I agree with what all of you have said before"

D2. Expressing disagreement (simple disagreement, without any justification): "I'm not too sure if I agree with ..."

D3. Maintaining social relations (messages relating to social aspects of the community):

"Marilena, don't worry about your difficulties in connecting everyday. The most important thing is that you respond to us"; "How was your meeting yesterday?"

D4. Introducing statements at the beginning or at the end of the message that aims to foster or maintain the relation with the group: "Good morning to everyone"; "I'm waiting for your answer"; "I hope it was clear"

One of the issues under discussion is the choice of the unit of analysis to perform content analysis (De Wever, Schellens, Valcke, Van Keer, 2006). Researchers can consider a sentence as a single unit of analysis (Fahy, 2001). Another option is to identify a consistent "theme" or "idea" (unit of meaning) in a message and to use this as the unit of analysis (Henri, 1992). Alternatively, a complete message that a student posts may serve as the unit of analysis and be coded, for example, to a certain "Phase" of knowledge construction in the discussion (Gunawardena, Lowe, \& Anderson, 1997)

We decided to apply the coding scheme to easily identifiable "segments" of the messages in the forums, considering this solution (Fahy, 2001) as more reliable. In particular, the segment in this study took the form of sentence units that were identifiable through the end punctuation (i.e. full stops, suspension dots, exclamations, and question marks) used by the authors of the messages themselves. The coding scheme was used to analyze a total of 442 messages and 2372 segments from the first discussion from each of the 14 groups. Independent judges coded the segments from the discourse data, reaching an inter-coder agreement of $87 \%$, calculated at subcategory level.

We analyzed differences in categories' distribution between groups (with and without role) using chisquare test. In order to analyze which category contributes significantly to global significant, we calculated adjusted standardized residuals (that are distributed as $\mathrm{z}$ ), comparing them with the value of critical $\mathrm{z}$ for $\mathrm{p}<.05$ and $\mathrm{p}<.01$.

\section{Study 2 Results}

Research Question 3: Does taking on a role influence the conversational functions of the messages students post, compared with those posted by students who do not take a role?

Table 7 Differences in Type of Messages Between Students With Role and Without Role (number of segments, percentage, adjusted standardized residuals)

\begin{tabular}{|c|c|c|c|c|c|c|c|c|c|c|c|c|c|c|}
\hline & \multicolumn{3}{|c|}{ Introducing } & \multicolumn{3}{|c|}{ Revising } & \multicolumn{3}{|c|}{$\begin{array}{l}\text { Evaluating } \\
\text { /Reflecting }\end{array}$} & \multicolumn{3}{|c|}{$\begin{array}{l}\text { Maintaining } \\
\text { Relationship }\end{array}$} & \multicolumn{2}{|c|}{ Total } \\
\hline & $\mathrm{N}$ & $\%$ & $\mathrm{z}$ & $\mathrm{N}$ & $\%$ & $\mathrm{z}$ & $\mathrm{N}$ & $\%$ & $\mathrm{z}$ & $\mathrm{N}$ & $\%$ & $\mathrm{z}$ & $\mathrm{N}$ & $\%$ \\
\hline $\begin{array}{c}\text { Students with role } \\
\quad(\mathrm{N}=53)\end{array}$ & 499 & $44 \%$ & $-4.79 * *$ & 209 & $18 \%$ & $2.66^{*}$ & 175 & $15 \%$ & $2.64 *$ & 249 & $22 \%$ & 1.24 & 1134 & $100 \%$ \\
\hline $\begin{array}{l}\text { Students without role } \\
\qquad(\mathrm{N}=90)\end{array}$ & 666 & $54 \%$ & $4.79 * *$ & 178 & $14 \%$ & $-2.66^{*}$ & 145 & $12 \%$ & $-2.64 *$ & 246 & $20 \%$ & -1.24 & 1238 & $100 \%$ \\
\hline
\end{tabular}

$* *=$ significant for $\mathrm{p}<.01 *=$ significant for $\mathrm{p}<.05$

The qualitative analysis of the discussions carried out by students shows that students with a role, besides writing more messages, tend to distribute more of their contributions throughout the four 
DOI 10.1007/s11412-015-9224-0

different categories $\left(X^{2}(3)=24.82 ; \mathrm{p}<.001\right)$. Analyzing Adjusted Standardized Residuals (Table 7) we can see that there are significant differences in "Introducing" $(\mathrm{p}<.01)$ and "Revising and Reflecting" categories $(\mathrm{p}<.05)$. Students without a role concentrate on introducing topic-related problem or content (Introducing $=54 \%$ ) (Table 7). Students with role also introduce messages with problem or contents (44\%) but, more so than their colleagues, are inclined to link to and build on contents already proposed, to improve or synthesize them (Revising $=18 \%$ vs. 14\%). Students with role are also more ready to reflect on process (Reflecting $=15 \%$ vs. $12 \%$ ) and, also if without a statistical significant difference, to foster relationships between group members (Maintaining relationship $=22 \%$ vs. $20 \%$ ).

Table 8 Differences in the Type of Messages Between Students With and Without Role: Subcategories of Category A, Introducing New Problems or Contents. (Numbers of segments, percentage of the total Segments and Adjusted Standardized Residuals).

\begin{tabular}{|c|c|c|c|c|c|c|c|c|c|c|c|c|c|c|c|c|c|}
\hline & \multicolumn{3}{|c|}{ Personal ideas } & \multicolumn{3}{|c|}{$\begin{array}{c}\text { Scientific } \\
\text { information }\end{array}$} & \multicolumn{3}{c|}{ Experiences } & \multicolumn{2}{c|}{$\begin{array}{c}\text { Information from } \\
\text { lectures }\end{array}$} & \multicolumn{3}{c|}{$\begin{array}{c}\text { Problems } \\
\text { Total } \\
\text { introducing }\end{array}$} \\
\hline $\begin{array}{c}\text { Students } \\
\text { with role } \\
\text { (N=53) }\end{array}$ & $\mathrm{N}$ & $\%$ & $\mathrm{z}$ & $\mathrm{N}$ & $\%$ & $\mathrm{z}$ & $\mathrm{N}$ & $\%$ & $\mathrm{z}$ & $\mathrm{N}$ & $\%$ & $\mathrm{z}$ & $\mathrm{N}$ & $\%$ & $\mathrm{z}$ & $\mathrm{N}$ & $\%$ \\
\hline $\begin{array}{c}\text { Students } \\
\text { without role } \\
\mathrm{N}=90)\end{array}$ & 533 & $43.1 \%$ & $3.78^{* *}$ & 22 & $1.8 \%$ & -1.62 & 94 & $7.8 \%$ & -0.81 & 4 & $0.3 \%$ & -1.93 & 13 & $1.1 \%$ & $-3.91 * *$ & 666 & $54 \%$ \\
\hline
\end{tabular}

$* *=$ significant for $\mathrm{p}<.01 *=$ significant for $\mathrm{p}<.05$

If we examine the categories and take into consideration the different subcategories, we can see that there are differences in distribution between students with and without role $\left(X^{2}(4)=24.72\right.$ $\mathrm{p}<.001$ ) in the category "Introducing new problems or contents" (Table 8). Differences are statistically significant $(\mathrm{p}<.01)$ for "Personal idea" and "Problems" categories. Students without role mainly tend to express their own, personal ideas (43\%). Students with role also express personal ideas $(31 \%)$, but they tend to propose more problems $(2.8 \%$ of their own segments vs. $1.1 \%$ of their own segments) more frequently than those without role.

Table 9 Differences in Type of Messages Between Students With and Without Role: Subcategories of Category B, Revising (Numbers of segments, percentage of the total Segments and Adjusted Standardized Residuals).

\begin{tabular}{|c|c|c|c|c|c|c|c|c|c|c|c|c|c|c|c|c|c|}
\hline & \multicolumn{3}{|c|}{$\begin{array}{c}\text { Elaborate their own } \\
\text { ideas }\end{array}$} & \multicolumn{3}{|c|}{$\begin{array}{c}\text { Elaborate others' } \\
\text { ideas }\end{array}$} & \multicolumn{3}{|c|}{ Synthesize } & \multicolumn{3}{|c|}{$\begin{array}{l}\text { Repeat others' } \\
\text { ideas }\end{array}$} & \multicolumn{3}{|c|}{$\begin{array}{c}\text { Repeat their own } \\
\text { ideas }\end{array}$} & \multicolumn{2}{|c|}{$\begin{array}{c}\text { Total } \\
\text { revising }\end{array}$} \\
\hline & $\mathrm{N}$ & $\%$ & $\mathrm{z}$ & $\mathrm{N}$ & $\%$ & $\mathrm{z}$ & $\mathrm{N}$ & $\%$ & $\mathrm{z}$ & $\mathrm{N}$ & $\%$ & $\mathrm{z}$ & $\mathrm{N}$ & $\%$ & $\mathrm{z}$ & $\mathrm{N}$ & $\%$ \\
\hline \begin{tabular}{|l|} 
Students with \\
role \\
$\quad(\mathrm{N}=53)$
\end{tabular} & 56 & $4.9 \%$ & $-5.98 * *$ & 26 & $2.3 \%$ & -2.48 & 104 & $9.2 \%$ & $9.93 * *$ & 16 & $1.4 \%$ & -1.55 & 7 & $0.6 \%$ & -0.84 & 209 & $18 \%$ \\
\hline $\begin{array}{c}\text { Students whitout } \\
\text { role } \\
(\mathrm{N}=90)\end{array}$ & 101 & $8.2 \%$ & $5.98 * *$ & 39 & $3.2 \%$ & 2.48 & 7 & $0.6 \%$ & $-9.93 * *$ & 22 & $1.8 \%$ & 1.55 & 9 & $0.7 \%$ & 0.84 & 178 & $14 \%$ \\
\hline
\end{tabular}

$* *=$ significant for $\mathrm{p}<.01 *=$ significant for $\mathrm{p}<.05$

In the "Revising" category (Table 9), there is also a significant difference in subcategories distribution $\left(X^{2}(4)=99.72 \mathrm{p}<.001\right)$. We find the main difference between students with and without role in the discursive function of synthesizing the discourse (with role $=9.2 \%$; without role $=0.6 \%$ ) in order to pose it again for the group's renewed attention. This is likely due to the presence of a specific role, in which synthesizing the group discussion every week is an explicitly stated 
DOI 10.1007/s11412-015-9224-0

responsibility. Another significant difference $(\mathrm{p}<.01)$ is in "Elaborating their own ideas" category. Students without a role are more focused on presenting their personal ideas, elaborating them in order to make them more comprehensible to others.

Table 10 Differences in Type of Messages Between Students With and Without Role: Subcategories of Category Area $\mathrm{C}$, Reflecting. (Numbers of segments, percentage of the total Segments and adjusted standardized residuals)

\begin{tabular}{|c|c|c|c|c|c|c|c|c|c|c|c|}
\hline & \multicolumn{3}{|c|}{$\begin{array}{c}\text { Metacognition on processes } \\
\text { and organization }\end{array}$} & \multicolumn{3}{|c|}{ Metacognition on contents } & \multicolumn{3}{|c|}{ Comments } & \multicolumn{2}{|c|}{ Total reflecting } \\
\hline & $\mathrm{N}$ & $\%$ & $\mathrm{Z}$ & $\mathrm{N}$ & $\%$ & $\mathrm{z}$ & $\mathrm{N}$ & $\%$ & $\mathrm{Z}$ & $\mathrm{N}$ & $\%$ \\
\hline $\begin{array}{l}\text { Students with role } \\
\qquad(\mathrm{N}=53)\end{array}$ & 68 & $6 \%$ & $5.47 * *$ & 40 & $4 \%$ & -1.65 & 67 & $5.9 \%$ & $-3.38 * *$ & 175 & $15 \%$ \\
\hline $\begin{array}{l}\text { Students whitout role } \\
\qquad(\mathrm{N}=90)\end{array}$ & 17 & $1.4 \%$ & $-5.47 * *$ & 45 & $4 \%$ & 1.65 & 83 & $6.7 \%$ & $3.38 * *$ & 145 & $12 \%$ \\
\hline
\end{tabular}

$* *=$ significant for $\mathrm{p}<.01 *=$ significant for $\mathrm{p}<.05$

In the "Reflecting" category (Table 10), differences between students with and without role are still significant $\left(X^{2}(2)=30.05 \mathrm{p}<.001\right)$. Calculating Adjusted Standardized Residuals, we can see that are significant differences in "Metacognition on processes and organization" and "Comments" categories $(\mathrm{p}<.01)$. Students with role are more willing than those without role to reflect on both the processes and the organization of activities (with role $=1.9 \%$; without role $=1.4 \%$ ). In either case, the reflective student with a role accepts responsibility for the collaborative knowledgebuilding process to a greater degree than do their colleagues without role. Students without role tend to comment notes more than their colleagues without role.

Table 11 Differences in Type of Messages Between Students With and Without Role: Subcategories of Category D, Maintaining Relationships . (Numbers of segments and percentage of the total Segments)

\begin{tabular}{|l|c|c|c|c|c|c|c|c|c|c|}
\hline Role status & \multicolumn{2}{|l|}{ Agreement } & \multicolumn{2}{|c|}{ Disagreement } & \multicolumn{2}{|c|}{ Social } & \multicolumn{2}{|c|}{$\begin{array}{c}\text { Activating } \\
\text { relationships }\end{array}$} & $\begin{array}{c}\text { Total maintaining } \\
\text { Relationships }\end{array}$ \\
\cline { 2 - 11 } & $N$ & $\%$ & $N$ & $\%$ & $N$ & $\%$ & $N$ & $\%$ & $N$ & $\%$ \\
\hline With role & 22 & $1.9 \%$ & 4 & $0.4 \%$ & 56 & $4.9 \%$ & 42 & $14.7 \%$ & 249 & $22 \%$ \\
\hline Without role & 37 & $3 \%$ & 8 & $0.6 \%$ & 56 & 4.5 & 69 & $11.7 \%$ & 246 & $20 \%$ \\
\hline
\end{tabular}

$\%=$ Percentage of the Total Segments

In the "Maintaining relationships" category (table 11), students with role tend to activate relationships (4.7\%) more frequently than do their without-role colleagues $(1.7 \%)$, but differences are not statistically significant $\left(X^{2}(3)=6.68, \mathrm{p}=.08\right)$.

Research Question 4: Are there differences between roles in the conversational functions of the messages posted?

Table 12 Differences in Type of Messages Between Roles (Means and percentage of the Total segments)

\begin{tabular}{|c|c|c|c|c|c|}
\hline Role Status & $\begin{array}{c}\text { Introducing } \\
M(\%)\end{array}$ & $\begin{array}{c}\text { Revising } \\
M(\%)\end{array}$ & $\begin{array}{c}\text { Reflecting } \\
M(\%)\end{array}$ & $\begin{array}{c}\text { Maintaining } \\
\text { relationships } \\
M(\%)\end{array}$ & $\begin{array}{l}\text { Total } \\
M(\%)\end{array}$ \\
\hline Map-responsible & $7.83(49 \%)$ & $1.58(10 \%)$ & $2.33(15 \%)$ & $4.08(26 \%)$ & $15.83(100 \%)$ \\
\hline Skeptic & $11.29(60 \%)$ & $2.36(12 \%)$ & $1.71(9 \%)$ & $3.57(19 \%)$ & $18.93(100 \%)$ \\
\hline
\end{tabular}


DOI 10.1007/s11412-015-9224-0

\begin{tabular}{lccccc}
\hline Synthesizer & $10.00(33 \%)$ & $\mathbf{9 . 7 9}(\mathbf{3 2 \%})$ & $5.50(18 \%)$ & $5.07(17 \%)$ & $30.36(100 \%)$ \\
\hline Social Tutor & $8.23(42 \%)$ & $1.54(8 \%)$ & $3.54(18 \%)$ & $\mathbf{6 . 2 3 ( 3 2 \% )}$ & $19.54(100 \%)$ \\
\hline
\end{tabular}

Table 12 reveals that, for all students enacting a role, introducing content is the main focus. However, there are some evident differences that we can attribute to correct role assumption: the Skeptic role $(M=11.29,60 \%)$ prioritizes working specifically on content, while the Synthesizer role $(M=9.79,32 \%)$ emphasizes revising content, particularly to synthesize it. The Social Tutor $(M=$ $6.23,32 \%)$ privileges giving oneself up to maintain relationships. The data for the Map-Responsible role does not reveal any peculiarity that distinguishes it from the other roles, because students who assume this role are responsible for acting at the end of the process rather than during the group discussion.

Students with roles acted enacted them to varying degrees of success in the different groups. Analyzing participation in quantitative terms, we see that there are differences between the groups, from an average of 1.35 notes written by each student in the group 3, to 6.46 notes per student for group 2; considering also the knowledge elaboration in terms of segments written, the groups range is from an average of 4.5 in the group 4 up to 32.77 in the group 2 (Table 13).

Table 13 Differences in writing between groups

\begin{tabular}{|l|c|c|}
\hline Group & Notes & Segments \\
& $M(\mathrm{SD})$ & $M(\mathrm{SD})$ \\
\hline 1 & $2.00(1.34)$ & $11.82(10.14)$ \\
\hline 2 & $6.46(5.87)$ & $35.42(26.29)$ \\
\hline 3 & $1.35(.50)$ & $8.67(5.05)$ \\
\hline 4 & $1.40(.52)$ & $4.50(2.99)$ \\
\hline 5 & $2.30(.95)$ & $18.40(19.20)$ \\
\hline 6 & $2.30(.82)$ & $11.80(5.69)$ \\
\hline 7 & $1.56(.53)$ & $7.56(3.40)$ \\
\hline 8 & $2.7(1.06)$ & $15.10(9.86)$ \\
\hline 9 & $4.45(2.07)$ & $32.45(28.32)$ \\
\hline 10 & $1.70(1.16)$ & $9.00(5.64)$ \\
\hline 11 & $5.91(5.45)$ & $28.00(36.74)$ \\
\hline 12 & $2.50(1.41)$ & $13.88(13.43)$ \\
\hline 13 & $1.91(.70)$ & $5.73(2.53)$ \\
\hline 14 & $5.10(3.69)$ & $24.30(19.93)$ \\
\hline Groups & $\mathbf{3 . 0 9}(\mathbf{3 . 1 3})$ & $\mathbf{1 6 . 5 9 ( 1 9 . 5 6 )}$ \\
\hline Mean & & \\
\hline
\end{tabular}

In order to better understand how students acted their role and which was their contribute to the knowledge-building activity we consider 2 groups at the opposite end of participation and elaboration of knowledge: with reference to the previous results, we can consider that in the group with a higher level of participation and knowledge elaboration, roles worked better than in the group with a lower level of participation and elaboration. We used this procedure: to select the group of lower level, we identified, using $25^{\text {th }}$ percentile $\left(\mathrm{P}^{25}=1.66\right)$ the groups with the lower level of participation, in terms of notes written (groups 3,4 and 7) and, among them, we selected the group with the lower level of elaboration of knowledge in terms of number of segments created (group 4). At the opposite end, using the 75 the percentile $\left(\mathrm{P}^{75}=4.61\right)$ we selected the groups with 
DOI 10.1007/s11412-015-9224-0

the upper level of participation (groups n. 2, 11 and 14), and among them, we selected the group with the higher level of elaboration of knowledge in terms of number of segments created (group 2).

Table 14 Differences in type of messages between group 4 and 2.

\begin{tabular}{|l|c|c|c|c|c|c|c|c|c|c|c|c|c|c|}
\hline Group & \multicolumn{3}{|c|}{ Introducing } & \multicolumn{3}{|c|}{ Revising } & \multicolumn{3}{c|}{$\begin{array}{c}\text { Maintaining } \\
\text { relationships }\end{array}$} & \multicolumn{2}{c|}{ Total } \\
\hline & $\mathrm{N}$ & $\%$ & $\mathrm{z}$ & $\mathrm{N}$ & $\%$ & $\mathrm{z}$ & $\mathrm{N}$ & $\%$ & $\mathrm{z}$ & $\mathrm{N}$ & $\%$ & $\mathrm{z}$ & $\mathrm{N}$ & $\%$ \\
\hline $4(9$ students $)$ & 35 & $83.3 \%$ & $6.02 * *$ & 5 & $11.9 \%$ & -0.72 & 1 & $2.4 \%$ & $-2.42^{*}$ & 1 & $2.4 \%$ & $-4.0 * *$ & 42 & $100 \%$ \\
\hline $2(12$ students $)$ & 150 & $35.3 \%$ & $-6.02^{* *}$ & 68 & $16.0 \%$ & 0.72 & 69 & $16.2 \%$ & $2.42 *$ & 134 & $31.5 \%$ & $4.0 * *$ & 425 & $100 \%$ \\
\hline
\end{tabular}

$* *=$ significant for $\mathrm{p}<.01 *=$ significant for $\mathrm{p}<.05$

Differences in distribution of global conversational functions among the two groups are statistically significant $\left(X^{2}(3)=38.5 ; \mathrm{p}<.001\right)$, and calculating Adjusted Standardized Residuals, we can see that there are significant differences in Introducing $(\mathrm{p}<.01)$, more used in the group 4 than in the group 2 , Maintaining relationships $(\mathrm{p}<.01)$, and in Reflecting $(\mathrm{p}<.05)$, more used in the group 2 than in the group 4.

Analyzing forum content we can see that, in group 4, knowledge building doe notbegin: the main global conversational function activated is "Introducing" and students simply enter their thoughts on what makes a good teacher $(83.3 \%$ of total segments, see table 14 ) with statements such as "in my opinion the good teacher must be a person who loves and knows the subject he teaches so as to convey to his students the passion and desire to learn" and "moreover she has to establish a relationship of mutual trust with the students, so that ..."

Revising is only expressed by segments aimed at clarifying their own ideas and there is no elaboration of the interventions of others (only one segment incorporates somehow the idea of other students). Each one merely reports his opinion as to perform a "task" assigned by the teacher. Students that agreed to take a role actually do not carry out it properly. The Synthesizer simply reports a brief summary of the ideas presented, without stressing or problematizing any aspect, and this action does not give rise to any debate. Only the Map-Responsible reponds to the synthesis by adding some concepts that she believed had been left out, and could be considered in order to organize the conceptual map better. The Social Tutor does not contribute towards to maintaining relationships, remaining at a formal level even in the formulas of closing of the notes (closing notes with formulations like "Yours truly"). The Skeptic merely posts his own idea "I believe that a good teacher should pursue his profession with a lot of passion to transmit knowledge and values to those who need to acquire the proper interest in the subject ...", without minimally trying to insinuate doubts or to problematize.

In group 2, all the global conversational functions are activated, mainly "Introducing" (35.3\% of total segments, see table 14) and "Maintaining relationship" (31.5\%); "Maintaining relationship" and "Reflecting" have been used more than in the group 2 and all students that accepted to act a role did it properly. Particularly relevant in this group is the role of the Social Tutor, who posts 22 notes articulated into 102 segments, of which $42(41 \%)$ were categorized as "Maintaining social 
DOI 10.1007/s11412-015-9224-0

relations," aimed both at encouraging the participation of the group, "continue to write your ideas, it's nice to debate with you ", and at maintaining the relationship with individual students, "Dear G. [...] I would be very pleased if in the next few days you tell us about your personal experience, both for educational purposes, and to get to know each other better," and "Bravo A., I see you've responded very promptly."

To motivate participation, the Social Tutor also expresses comments and reflections on the content and process: "Dear girls, this debate seems to me very interesting. I invite all others to join S. and E. and express what they think, we are here to discuss with each other, and about this I launch a new provocation...". The climate within the group is marked by cordiality and there are many informal interactions and salutations used.

At the end of the first week, the Synthesizer produces a complete and articulated synthesis. This contributes to the resumption of a debate, acting as a rise-above note. The debate focuses both on the synthesis itself, in order to integrate it ("I wanted to add that a good teacher should facilitate integration among students making them understand each other's differences, especially between different cultures..."), and on issues that are highlighted from it ("I would like to add to the synthesis of E., I do not believe that a good teacher should not be authoritarian, but must know how to manage his authority to prevent it transform neither in terror nor in too much kindness ..."). The synthesis produces new threads, which are expressed through different types of conversational functions, not limited only to the introduction of new concepts but elaborating, evaluating and commenting own and others' thinking.

Interesting is the role of the Skeptic, which participates to this first debate with only four notes, but all very long and articulated, divided in 28 segments. Two of these notes contain statements that can be called "provocateurs" aimed to destabilize the common idea until then discussed: "One thing makes me doubt, for example E. says that a good teacher must teach to his pupils, but without imposing, I wanted to know: do not you think that maybe, however, a good teacher should instead impose himself (of course do not overdo it), especially in middle and high schools to ensure that all of his students go on?", and more, in another post: "Some points of this sentence made me think: He must transmit the right values... that puzzles me, I believe that a good teacher should confine himself only to teach the boy / child his subject and especially to let him reason, knowing how to use his head, and do not transmit values, there is the family for this, and what is happening now more and more is that: parents who delegate to the figure of the teacher the role of educating, failing in their role as a parent ". These statements generate a detailed discussion in the group (with 10 notes composed by 58 segments) about the topic authority-authoritarianism and the distinction between the role of teacher and the role of parents.

In this group the high participation and the appropriate acting of students with role highly contributed to the common knowledge building.

\section{General Discussion}

The main goals of the two studies presented were to investigate: 1) if taking a role in a group in an online course leads to a higher level of participation in terms of knowledge-building activity writing and reading levels; and 2) which kind of role fosters the highest level of participation 3) if taking on a role influences the conversational functions of the messages students post compared with those posted by students who do not take a role 4 ) if there are there also differences between roles in the conversational functions of the messages posted.

Concerning the first research question, the results (Study 1) show that students who assume roles in an online course are more active in terms of writing and reading activity in the online 
DOI 10.1007/s11412-015-9224-0

environment. Assuming a role seems to be, then, a "triggering event" (Garrison, Anderson, \& Archer, 2000) for the students that promotes participation. In order to explain this result, we can distinguish between different levels of analysis, including the relationship, motivational, and metacognitive levels.

At the relationship level, the assigned roles seemed to work as interaction organizers, indicating the nature of the contributions expected from each role-taking participant in the online discussion. Along these lines, De Wever, Van Keer, Schellens, and Valke (2010) state that roles support the coordination and promotion of effective interaction patterns, as shown by the positive effects in improving task performance and satisfaction among participants, while also alleviating problems of non-participation and domination of the interaction by one group member.

At the motivational level, to understand why role-taking can activate a higher level of participation we can consider the analysis of Strijbos and De Laat (2010) highlighting that during a collaborative learning activity, a student is oriented toward individual and group goals, but not necessarily both kinds of goals and not at the same level of commitment. For instance, lurkers can be considered to be more oriented toward individual goals, because they invest a minimal amount of effort in the collaborative activity. It is plausible that taking a role can stimulate students to assume more involvement in their own learning processes, take personal control of this learning, and change their prior orientation toward integrating personal and group goals. The interdependence created through assigned roles can help to deepen students' understanding of the importance of working together in a joint effort.

At the metacognitive level, scripted roles allow individual students to understand how to position themselves with regard to the group's engagement in the knowledge building process in asynchronous discussion. Students accept a specific cognitive responsibility to create a strategy of work consistent with the role attributed. Scardamalia (2002) expresses a similar idea when she speaks about the "collective cognitive responsibility" that emerges when students participate in a knowledge-building community. Scardamalia does not mention the assumption of roles by students, but the concept of an online activity orchestrated with interdependent roles seems useful for knowledge building, taking care to avoid "reduction to activities" - reducing the emergent, selforganizing nature of students' knowledge-building discourse to role-taking activities (Bereiter, 2002). The notion of scripting and orchestration in this paper aims to scaffold the knowledge building process without "over-scripting" or inhibiting the student's self-regulated application of higher-level internal collaboration processes (Dillenbourg, 2002; Fischer, Kollar, Stegmann, \& Wecker, 2013). Scripted roles specify the kinds of conversational functions that are considered relevant for the collaborative learning and knowledge building (Wise et al. 2012), the likes of which learners rarely engage in spontaneously, such as giving explanations, constructing arguments, and resolving conflicts productively (Strjibos \& Weinberger, 2010).

Our results highlight also that students' writing and reading activity increases when they assume roles and continues to remain high even when they abandon these roles (in Module 3). An interesting explanation of this result can be connected to the analysis proposed by Strijbos and De Laat (2010). The authors distinguish three different levels in the use of roles to support collaborative learning: role as a task (micro-level), role as a pattern (meso-level) and role as a stance (macro-level). At the micro-level, a single task, intended as a piece of work to be attended to in the time required, is assigned. In this case, the role can be product-oriented (e.g. the "Starter," who is given the task to introduce a question at the beginning of the online discussion) or processoriented (e.g. the "Task Manager," who helps other group members to remain focused on the issue being discussed). At the meso-level, a pattern of multiple tasks is assigned. These tasks are focused on the product, the process, or a combination of both. At the macro-level, the role consists of a stance comprised by an individual's participative style, which is based on that student's attitude toward the task and the collaborative learning (e.g. the lurker is a role included in this level). The 
DOI 10.1007/s11412-015-9224-0

four roles introduced in the present study can be considered at the micro-level. In two cases, the roles are product-oriented (Synthesizer and Map-Responsible), while, in the remaining two cases, they are process-oriented (Social Tutor and Skeptic). The effective integration of these roles as experienced by the students allows the practice of new and effective strategies of online work that are sustained in the ensuing modules even without role attribution, with positive effects on participation.

Regarding the second research question, the results (Study 1) show that the role of "Synthesizer" is the most active among the roles in terms of writing and the second most active for reading activity. As suggested by De Wever, Van Keer, Schellens, \& Valke (2010), the role of "Synthesizer" (or "Summarizer," as they called it) requires a stronger focus on building upon others' contributions, whereas other roles require less building on previous messages (e.g. initiating topics and starting new discussions, as in the Social Tutor, Map-Responsible, and Skeptic roles in our study). Interestingly, the aforementioned authors report that the Summarizer role has the largest positive effect on the level of knowledge construction (Schellen, Van Keer \& Valcke, 2005). Our findings are consistent with previous research. When a student works to synthesize an online discussion, this student takes on a responsibility to define the advancements in the community's knowledge. Thus, the Synthesizer may stimulate the knowledge-building process in the community by more frequently making written contributions and may analyze the evolution of knowledge creation through high levels of reading activity. We have seen also that students that assumed the role of Social Tutor read more than the others roles. Probably who play this role is interested to verify, through the content of the messages, the participation of the other members of the group and the presence of a positive "climate" in the group.

In addition, with reference to the third research question (Study 2), we note with interest that students with roles tended to vary the nature of their contributions, with the use of different global conversational functions more so than students without roles. Additionally, the content analysis confirms that these students effectively engaged in specific conversational functions that are considered relevant for the collaborative process and knowledge building: they tend more to propose problems, are more engaged in synthesizing the discourse, and are more willing to reflect on both processes and the organization of activities. These activities seems to be consistent with the principle of "epistemic agency" (Scardamalia, 2002) describing students in a knowledge building community as able to define their goal of inquiry, to identify methods to achieve them, to see the gaps in the one's own knowledge and weaknesses in collaboration activities. In other words, students in our study assumed through their roles the "collective cognitive responsibility" for knowledge building (Scardamalia, 2002). It is also consistent with Strijbos, Martens, Jochems, \& Broers (2004) claiming that roles increase students' awareness of active collaboration and this may enhance knowledge construction (De Wever at al., 2010).

Finally, with reference to the fourth question, results (Study 2) show that for all students enacting a role, "Introducing problems and content" are the main global conversational function activated However, there are some evident differences that we can attribute to correct role assumption: the Skeptic role prioritizes working specifically on content, while the Synthesizer role emphasizes revising content, particularly to a synthetic end. The Social Tutor privileges giving oneself up to maintain relationships. The data for the Map-Responsible role does not reveal any peculiarity that distinguishes it from the other roles, because students who assume this role are responsible for acting at the end of the process rather than during the group discussion. These results show that students assumed the roles that were proposed to them and performed the global conversational functions, in particular those in the roles of Skeptic, Synthesizer and Social Tutor. We have seen also in the analysis of the group 4 interactions, how these roles worked in an interdependent way to support knowledge building activity in the group. But, as stated by Spada (2010), a relevant questions in analyzing the function of roles in on line learning concerns which roles might have 
DOI 10.1007/s11412-015-9224-0

favorable effects on collaborative learning and, in our case, knowledge building. Referring to a rating scheme to assess relevant aspect of collaborative process quality, developed by Meier, Spada and Rummel (2007), Spada (2010) highlights five broad aspects of the collaboration process:

1. Communication (sustaining mutual understanding-grounding; dialogue managementcoordinating the discourse process);

2. Joint information processing (information pooling-contributing and eliciting distributed information; reaching consensus-discussing and critically evaluating information);

3. Coordination (task division, time management, technical coordination);

4. Constructive interpersonal relationship;

5. Motivation.

If we look at the roles designed in the present research, we can see that they have some connections with these aspects. The Social Tutor works to construct and maintain interpersonal relationships and the Synthesizer, Map-Responsible and Skeptic worked on different aspects of joint information processing. The roles assumed, then, are functional, in terms of interdependent conversational functions to an effective collaborative process, also if other roles for communication, coordination and motivation could be effectively designed.

\section{Conclusions}

If the studies that analyzed role taking in blended courses highlight that the assumption of a scripted role guides the activity of individual students, and regulates their interactions within the group, past work has not explicitly focused on how to design and operationalize roles explicitly oriented to collaborative knowledge building. The present study demonstrated that defining roles in terms of "conversational functions" can create an interdependence among the participants oriented toward knowledge building.

In particular it was showed that:

(1) The participation level got quantitatively higher in the condition of role taking in comparison with the no-role condition.

(2) Roles of Synthesizer and Social Tutor led students in higher participation of writing or reading.

(3) Taking on roles led students to vary the nature of their contributions, in comparison with those in the no-role condition.

(4) Different types of roles differently stimulated kinds of messages posted.

These results can be useful for large University courses, both blended and full online, when it is difficult for teachers to model knowledge building in all different groups.. Teachers can introduce scripted roles for activating students to share a common responsibility for knowledge building. Of course it is necessary to take into account that the roles of Synthesizer, Skeptical and Social Tutor can be useful both for blended and full on line courses, and that one role, Map Responsible, was specifically designed for face to face meeting in the blended courses. But is possible to redefine this kind of role involving him in synchronous videoconference sessions for sharing with a larger audience the knowledge created by his group.

The present study has some limitations. First, the membership of the subjects to the same university limits the generalizability of the results. Second, the limited number of males involved may have had an effect on role assumption, particularly with the relationship aspects. This implies that, in a possible replication of this work, diversifying the universities involved and balancing the gender composition would increase rigor. A third limitation concerns the strategy of "pooled results" used: the students in the different conditions compared (with role or without role) are 
DOI 10.1007/s11412-015-9224-0

nested within different groups. This strategy do not allow us to analyze the effect of the role assumption in terms of patterns of interactions emerged in different groups, but it is important to consider that this was not a matter of the present study.

The contributions to the literature and for future research of this study can be identified in these main aspects:

- having a scripted role such as that introduced in this study stimulates students to a higher level of participation in knowledge building from the quantitative and qualitative point of view: it could be interesting to compare online courses implemented from one hand with the perspective of the "scripted roles" and, from the other hand, with the perspective of the "emergent roles", to analyze the differences in terms of participation;

it would also be interesting, in a blended course, to consider the relations of scripted and emergent roles and to examine if students with scripted roles assigned continue their earlier roles or taking up new roles when they ended the period of work with the scripted roles assigned;

- Synthesizer and Social Tutor seems to have pivotal functions in online discussion: it could be interesting to understand in more specific ways which are the specific moments of the on line discussion when they give their contribute, to analyze in particular which are the effects of their interventions, and to identify which kind of interventions are particularly effective in sustaining knowledge building;

- other roles specifically designed for knowledge building can be explored in the future, e.g. roles connected to the specific conversational function such as using theory to ground the discussion or bring in relevant external sources (Wise et. al 2012);

- the coding scheme employed allowed to analyze which global and specific kind of conversational functions have been used by students with roles and that typically characterized each specific role, to understand his peculiar contribution to the knowledge building process: an interesting question concerns the analysis of the effects of the roles attributed to the students in terms of patterns of interaction emerging in the groups. Considering the higher level of participation of the students with role, in fact, it is interesting to understand how the presence of roles can alter the dynamic of the discussions. It could be possible, for instance to examine what happens with regard of the overall participation of all the students in the group, or with reference to the way in which on line discussion works (e.g. conflict management, negotiation process to reach consensus, etc.).

More future research is needed to explore these questions, to understand how the role taking perspective can support knowledge building in on line courses.

\section{References}

Bereiter, C. (2002). Education and mind in the knowledge age. Mahwah, NJ: Lawrence Erlbaum Associates.

Black, E., Dawson, K., \& Priem, J. (2008). Data for free: Using LMS activity logs to measure community in an online course. Internet and Higher Education, 11(2), 65-70.

Brewer, S., \& Klein, J. (2006). Type of positive interdependence and affiliation motive in an asynchronous, collaborative learning environment. Educational Technology Research \& Development, 54(4), 331-354.

Cacciamani, S. Cesareni, D. Martini, F., Ferrini, T., \& Fujita N. (2012). Influence of participation, facilitator styles, and metacognitive reflection on knowledge building in online university courses. Computers and Education, 58(3), 874-884. 
DOI 10.1007/s11412-015-9224-0

De Wever, B., Schellens, T., Valke, M., \&Van Keer, H. (2006). Content analysis schemes to analyze transcripts of online asynchronous discussion groups: A review. Computers \& Education, 46, 6-28.

De Wever, B., Van Keer, H., Schellens, T., \& Valke, M. (2010). Role as a structuring tool in online discussion groups: The differential impact of different roles on social knowledge construction. Computers in Human Behavior, 26, 516-523.

Dillenbourg, P. (2002). Over-scripting in CSCL. In P. A. Kirschner (Ed.), Three worlds of CSCL: Can we support CSCL (pp. 61-91). Heerlen: Open University of the Netherlands.

Fahy, P. J. (2006). Addressing some common problems in transcript analysis. The International Review of Research in Open and Distance Learning, 1(2). Retrieved October, ${ }^{\text {rd }}$, 2014 from http://www.irrodl.org/index.php/irrodl/article/view/321/531

Fischer, F., Kollar, I., Stegmann, K., \& Wecker, C. (2013). Toward a script theory of guidance in computer-supported collaborative learning. Educational Psychologist, 48(1), 56-66.

Garrison, D. R., Anderson, T., \& Archer, W. (2000). Critical inquiry in a text-based environment: Computer conferencing in higher education. The Internet and Higher Education, 2(2-3), 87-105.

Gunawardena, C. N., Lowe, C. A., \& Anderson, T. (1997). Analysis of a global online debate and the development of an interaction analysis model for examining social construction of knowledge in computer conferencing. Journal of Educational Computing Research, 17(4), $397-431$.

Hare, A.P. (1994). Types of roles in small groups: A bit of history and a current perspective. Small Group Research, 25, 443-448.

Henri, F. (1992). Computer conferencing and content analysis. In Collaborative learning through computer conferencing (pp. 117-136). Springer Berlin Heidelberg.

Hickey, D. T., McWilliams, J., \& Honeyford, M. (2011). Reading Moby-Dick in a participatory culture: Organizing assessment for engagement in a new media era. Journal of Educational Computing Research, 45(2), 247-263.

Hrastinski, S. (2008). Asynchronous \& synchronous e-learning. Educause Quarterly, 4, 51-55.

Kollar, I., Fischer, F., \& Hesse, F. W. (2006). Collaboration scripts - a conceptual analysis. Educational Psychology Review, 18(2), 159-185.

Meier, A., Spada, H., \& Rummel, N. (2007). Evaluating collaboration: A rating scheme for assessing the quality of collaborative process. International Journal of Computer-Supported Collaborative Learning, 2, 63-86.

Morris, M., \& Ogan, C. (1996). The Internet as mass medium. Journal of Computer-Mediated Communication, 1(4). Retrieved from http://jcmc.indiana.edu/vol1/issue4/morris.htmlMuukkonen, H., Hakkarainen, K., \& Lakkala, M. (2004). Computer-mediated progressive inquiry in higher education. In T. S. Roberts (Ed.), Online Collaborative Learning: Theory and Practice (pp. 28-53). Hershey, PA: Information Science Publishing

Nonnecke, B., \& Preece, J. (2001). Why lurkers lurk. Paper presented at the Americas Conference on Information Systems. Boston. Retrieved from http://skeeter.socs.uoguelph.ca/ nonnecke//research/whylurk.pdf 
DOI 10.1007/s11412-015-9224-0

O' Reilly, T. (2005). What is Web 2.0. Design patterns and business models for the next generation of software. Retrieved from http://oreilly.com/web2/archive/what-is-web-20.html

Pozzi, F. (2011) The impact of scripted roles on online collaborative learning processes. International Journal of Computer-Supported Collaborative Learning, 6, 471-484.

Preece, J., Nonnecke, B., \& Andrews, D. (2004). The top five reasons for lurking: improving community experience for everyone. Computers in Human Behavior, 20, 201-223.

Scardamalia, M. (2002). Collective cognitive responsibility for the advancement of knowledge. In B. Smith (Ed.), Liberal education in a knowledge society (pp.76-98). Chicago, IL: Open Court.

Scardamalia, M. \& Bereiter, C. (1999). Schools as knowledge-building organizations. In D. Keating \& C. Hertzman (Eds.), Today's children, tomorrow's society: The developmental Health and Wealth of Nations (pp.274-289). New York, NY: Guilford.

Scardamalia, M. \& Bereiter, C. (2006). Knowledge building: Theory, pedagogy, and technology. In K. Sawyer (Ed.), Cambridge Handbook of the Learning Sciences. New York: Cambridge University Press.

Scardamalia, M. \& Bereiter, C. (2010). A brief history of Knowledge Building. Canadian Journal of Learning and Technology 36(1). Retrieved from http://www.cjlt.ca/index.php/cjlt/article/view/574

Schellens, T, Van Keer, H., \&Valcke, M. (2005). The impact of role assignment on knowledge construction in asynchronous discussion groups: A multilevel analysis. Small Group Research, 36, 704-745.

Selwyn, N. (2012). I Social Media nell'educazione formale e informale tra potenzialità e realtà. Tecnologie didattiche, 20(1), 4-10.

Spada, H. (2010). Of scripts, roles, positions and models. Computers in Human Behavior, 26, 547550.

Spadaro, P. F., Sansone, N., \& Ligorio, M.B. (2009). Role-taking for knowledge building in a blended learning course. Je-LKS, 5(3), 11-21.

Stahl, G. (2006). Group cognition: Computer support for building collaborative knowledge. Cambridge, MA: MIT Press.

Strijbos, J. W., Martens, R., Jochems, W. M. G., \& Broers, N.J. (2004). The effect of functional roles on group efficiency: Using multilevel modeling and content analysis to investigate computer-supported collaboration in small groups. Small Group Research, 35(2), 195-229.

Strijbos, J. W. \& De Laat, M. F. (2010). Developing the role concept for computer-supported collaborative learning: An explorative synthesis. Computers in Human Behavior, 26, 495-505.

Strijbos, J. W. \& Weinberger, A. (2010). Emerging and scripted roles in computer-supported collaborative learning. Computers in Human Behavior, 26, 491-494.

Wallace, R. (2003). Online learning in higher education: A review of research on interactions among teachers and students. Education, Communication and Information, 3(2), 241-280.

Weinberger, A., Stegman, K, \& Fisher, F. (2010). Learning to argue online: scripted groups surpass individuals (unscripted groups not). Computers in Human Behavior, 26, 506-515.

Wilensky, U. \& Stroup, W. (1999). Learning through participatory simulations: Network-based design for systems learning in classrooms. Proceedings of CSCL '99, Computer-Supported Collaborative Learning, Stanford University. Retrieved from http://ccl.northwestern.edu/papers/partsims/cscl/

Wise, A. F., Chiu, M. M. (2011) Analyzing temporal patterns of knowledge construction in a rolebased online discussion. International Journal of Computer-Supported Collaborative Learning, 6, 445-470 
DOI 10.1007/s11412-015-9224-0

Wise, A. F., Saghafian, M., \& Padmanabhan, P. (2012). Towards more precise design guidance: specifying and testing the functions of assigned student roles in online discussions. Educational Technology Research and Development, 60(1), 55-82.

Xenos, M. and Foot, K. (2008). Not your father's Internet: The generation gap in online politics. In W. L. Bennett (Ed.), Civic life online: Learning how digital media can engage youth (pp.5170). Cambridge, MA: The MIT Press. 